\title{
Sudden Cardiac Death in Patients with Chronic Kidney Disease: Prevention Is the sine qua non
}

\author{
Mehmet Kanbay ${ }^{a}$ Yalcin Solak ${ }^{b}$ Adrian Covic $^{c}$ David Goldsmith ${ }^{d}$ \\ ${ }^{a}$ Division of Nephrology, Department of Medicine, Kayseri Training and Research Hospital, Kayseri, and \\ ${ }^{b}$ Division of Nephrology, Department of Medicine, Selcuk University, Meram School of Medicine, Konya, Turkey; \\ 'Nephrology Clinic, Dialysis and Renal Transplant Center, 'C.I. PARHON' University Hospital, 'Gr. T. Popa' University of \\ Medicine and Pharmacy, lasi, Romania; ${ }^{d}$ Renal Unit at Guy's and St Thomas' NHS Foundation Hospital, London, UK
}

\section{Key Words}

Chronic kidney disease $\cdot$ Sudden cardiac death ·

Prevention

\begin{abstract}
Despite developments in the technology of dialysis procedures and improvements in the understanding of systemic derangements related to chronic kidney disease (CKD), cardiovascular disease is the major cause of death. Unfortunate$l y$, the leading subset of cardiovascular disease death is sudden cardiac death (SCD). To date much effort has been exerted to figure out the clues pointing to the risk of future development of SCD in patients with CKD. However, none of these factors satisfactorily detects a truly vulnerable dialysis patient. Thus, recently, it has been advocated that a combination of noninvasive risk assessment methods, carefully chosen to reflect the different aspects of the underlying pathology and changes in the myocardial substrate in CKD, could help to identify patients at high risk of SCD within the CKD. In this review, we aimed to summarize what is known about risk stratification of patients with CKD and appropriate prevention strategies with a special emphasis on recent developments and the use of complimentary tests perhaps as a risk prediction rule.

Copyright $\odot 2011$ S. Karger AG, Basel
\end{abstract}

\section{Introduction}

Despite ongoing developments in the technology of dialysis procedures and improvements in the understanding of systemic derangements related to chronic kidney disease (CKD), life expectancy of dialysis patients is still far below that of the general population. The major cause of death in patients with CKD is cardiovascular disease. Unfortunately, the leading subset of cardiovascular causes of death is sudden cardiac death (SCD). Mortality attributed to SCD is estimated at 49.5 per 1,000 patientyears accounting for 595 of cardiac-related deaths [1]. As the name implies, SCD refers to the unexpected natural death from a cardiac cause within a short time period, generally $\leq 1 \mathrm{~h}$ from the onset of symptoms, in a person without any prior condition that would appear fatal. One of the difficulties at the outset is the lack of consensus about the definition of SCD. The term 'unexpected' in the above definition poses the greatest difficulty for the physicians dealing with patients with CKD. Given the high mortality of patients receiving renal replacement therapy, in what sense can death be completely unexpected? Although there is a great excess of sudden death in subjects with CKD, it is still not completely possible to accurately describe which subjects from a population are most sus-

\section{KARGER \\ Fax +4161306 1234 \\ E-Mail karger@karger.ch}

www.karger.com
(C) 2011 S. Karger AG, Basel

1420-4096/11/0344-0269\$38.00/0

Accessible online at:

www.karger.com/kbr
Mehmet Kanbay, MD

Alparslan Mahallesi, Umit sokak

No:25/14, Melikgazi

Kayseri (Turkey)

Tel. +90 505266 8866, E-Mail drkanbay@yahoo.com 
ceptible. It is the aim of this mini-review to try to characterize risk assessment based on solid clinical and laboratory parameters.

The outcome of cardiac arrest is dismal in dialysis patients. Karnik et al. [2] reported that the 48-hour mortality rate of 400 dialysis patients with cardiac arrest was $60 \%$. Thus, it is of limited value to try to rescue the dialysis patient surviving a cardiac arrest after the incident in terms of survival advantage. The critical approach should be the determination of the most vulnerable patient in terms of SCD risk and using this knowledge then to take effective measures to diminish the risk of or prevent the catastrophic event, if possible. In this context, effective risk stratification of patients with CKD is of utmost importance and has the potential of being the second major improvement after the advent of renal replacement therapies in terms of survival advantage.

To date much effort has been exerted to figure out the clues pointing to the risk of future development of SCD in patients with CKD. The factors which were associated with the development of SCD included the same traditional risk factors for SCD as seen in the general population. However, none of these factors satisfactorily detects a truly vulnerable dialysis patient. Thus, recently, it has been advocated that a combination of noninvasive risk assessment methods, carefully chosen to reflect the different aspects of the underlying pathology and changes in the myocardial substrate in end-stage renal disease (ESRD), could help to identify patients at high risk of SCD within the CKD and ESRD cohorts [3]. In an ideal world, there would be an SCD propensity score, against which to frame any future trials, or emergent interventional therapy.

In this review, we aimed to summarize what is known about risk stratification of patients with CKD and appropriate prevention strategies with a special emphasis on recent developments and the use of complimentary tests perhaps as a risk prediction rule.

\section{Causes of SCD in Patients with CKD}

SCD is the single most common form of death in dialysis patients, accounting for approximately $30 \%$ of allcause deaths [4]. What makes this special dialysis cohort unique is not only the marked increase in SCD frequency seen, but also the major differences in risk factors related to SCD compared to the general population. In the general population, most $S C D$ cases $(\geq 80 \%)$ have associated coronary artery disease [5]. Despite a high incidence of coronary artery disease and a great burden of related traditional cardiovascular risk factors, the rate of SCD in ESRD patients far exceeds the frequency of coronary events. Furthermore, this increased risk persists after successful revascularization in contrast to the general population [6]. This means that some factors other than the traditional cardiovascular risk factors may be responsible for the increased risk of SCD in patients with CKD. Characterization of these factors is crucial to take effective preventive measures against SCD.

\section{Risk Factors for SCD Unique to the ESRD Population}

\section{Uremic Cardiomyopathy}

Even with intermittent renal replacement therapy, dialysis patients are subject to increased levels of uremia compared to persons without renal disease. Long-standing uremia leads to 'uremic cardiomyopathy', with typical changes of diffuse myocardial fibrosis and capillary rarefaction [7]. Fibrosis in the myocardium can lead to slowing of conduction and increased dispersion of repolarization, both of which can be proarrhythmic [8]. Microvessel disease and capillary deficit (capillary/ myocyte mismatch) is another unique feature of uremic cardiomyopathy [9]. This results from inadequate capillary growth in response to cardiac muscle hypertrophy. During conditions demanding increased oxygen consumption, relative global hypoxia ensues and renders the heart more susceptible to arrhythmias [10]. Short intermittent hemodialysis treatments exert significant hemodynamic effects, and $20-30 \%$ of treatments are additionally complicated by episodes of significant intradialytic hypotension. This in turn coupled with microvascular changes produces local ischemia. Attacks of local ischemia may result in regional wall motion abnormalities even after return of the normal perfusion [11]. This so-called myocardial stunning when it occurred in a repetitive manner may lead to constant changes in the myocardium which translate into practice as reduced ejection fraction [12]. Burton et al. [13] also showed that the presence of myocardial stunning was associated with increased mortality at 12 months and age, higher ultrafiltration volumes, intradialytic hypotension, and cardiac troponin $\mathrm{T}$ levels were independent determinants of it. Despite these findings, the reality is that very many patients have satisfactorily been managed by dialysis for decades, and SCD is as common in peritoneal dialysis as in hemodialysis. 


\section{Rapid Volume and Electrolyte Shifts}

One of the major deviations from normal physiology in dialysis patients is rapid shifts in electrolytes and fluid volume in the body during and between hemodialysis sessions. This major difference has been supposed to be among the facilitating factors of SCD in this cohort. The most compelling evidence for the role of dialysis in SCD is that there appears to be a temporal relationship between the days of dialysis and SCD. SCD is particularly frequent during the first $12 \mathrm{~h}$ of commencing dialysis and the last $12 \mathrm{~h}$ preceding the next dialysis session after the long interval of a week [14]. This observation supports the notion that rapid reductions in electrolyte composition, especially potassium, may provoke arrhythmias. Dialysate composition may also contribute to rapid transition of electrolyte and fluid thereby increasing the risk of SCD. In their recent study, Pun et al. [15] showed that low potassium and/or low calcium dialysate was an independent risk factor for SCD. The same applies to increased interdialytic weight gain. However, while this is undoubtedly correct, the SCD rates in peritoneal dialysis patients are also very high.

\section{Derangements in Calcium and Phosphorus Metabolism}

Hyperphosphatemia in hemodialysis patients has been shown to be an independent risk predictor of coronary and sudden death [16]. Some explanatory mechanisms have been put forward including changes in intracellular handling of calcium and resulting interference with electrical stability, abnormal conduction and late potential formation due to calcium-phosphate precipitation [17]. No study to date has demonstrated a beneficial effect of lowering serum phosphate and calcium-phosphate product on SCD in ESRD patients.

\section{Electrocardiographic Parameters}

\section{QT Interval and Dispersion}

QT interval and dispersion are among the most commonly studied ECG markers predicting SCD. QT dispersion is defined as the difference between the longest and shortest QT intervals in a 12-lead ECG recording.

Hemodialysis patients have prolonged QT interval and QT dispersion values [18]. Furthermore, the hemodialysis procedure also causes deleterious effects on QT dispersion per se, that is a single session leads to a further increase in an already increased QT dispersion [19]. More importantly, dialysis patients with QT dispersion longer than $74 \mathrm{~ms}$ were shown to be at risk for serious ventricular arrhythmias or sudden death [20]. A number of factors including age, low-density lipoprotein cholesterol, calcium $\times$ phosphorus product, and parathyroid hormone levels have been shown to be significant predictors of QT dispersion in hemodialysis patients [21]. Wu et al. [22] showed a relationship between increased iron stores and QTc dispersion in peritoneal dialysis patients. In an intervention trial in hemodialysis patients with secondary hyperparathyroidism, Kim et al. [23] found that calcitriol treatment led to a decrease in QTc dispersion without changes in serum calcium and phosphorus levels. Genovesi et al. [24] showed that the combination of low potassium and low calcium dialysate was associated with the longest QT values during and immediately after the hemodialysis session.

Taken together, QTc dispersion is a risk predictor of SCD in patients with CKD, which is influenced by a host of factors including dialysate electrolyte composition, anemia and calcium-phosphorus metabolism parameters.

\section{Heart Rate Variability}

Heart rate variability (HRV) is a measure of physiological variation in the beat-to-beat interval of heart rate [3]. HRV reflects the imbalance between the sympathetic and parasympathetic control of the heart. This parameter has been used to evaluate and quantify the cardiac risk associated with a variety of conditions including cardiac disorders, stroke, multiple sclerosis and diabetes [25]. Reduced HRV has been established as a significant independent risk factor for higher mortality and cardiac death in cardiovascular disease and normal populations [26].

In a recent prospective study, cardiac autonomic imbalance expressed as reduced HRV was found to be able to predict SCD among hemodialysis patients with left ventricular hypertrophy [27]. Another study by Oikawa et al. [28] showed that decreased HRV on 24-hour ambulatory electrocardiography is an independent predictor of all-cause and cardiovascular death (SCD was one fourth of all cardiovascular deaths). In addition, Roumelioti et al. [29] showed that patients with stage 4 and 5 CKD exhibited dysregulation of the autonomic nervous system tone manifesting as a failure to increase HRV during wakefulness and sleep. HRV variables were significantly associated with diabetic status, higher periodic limb movement indices and lower bicarbonate levels.

Furuland et al. [30] found that even predialytic CKD patients had reduced HRV which could partially be reversed by anemia management. In a recent small study, it 
was shown that renal transplantation led to significant improvements in HRV compared to pretransplant values [31]. Rubinger et al. [32] also showed that renal transplantation improved HRV and restored baroreflex function to a near-normal range.

\section{T Wave Alternans}

T wave alternans, also called repolarization alternans, is a periodic beat-to-beat variation in the morphology, amplitude or timing of the T waves in ECG. Microvolt T wave alternans is a noninvasive technique of assessing abnormal left ventricular repolarization and hence the risk of ventricular tachyarrhythmias [3]. After the pilot study by Friedman et al. [33], which showed abnormal cardiac repolarization using microvolt wave alternans in hemodialysis patients, a number of recent studies investigated this issue in patients with CKD. Patel et al. [34] compared patients with ESRD to patients with left ventricular hypertrophy. The authors found that abnormal microvolt $\mathrm{T}$ wave alternans was more common among ESRD patients and was significantly associated with uremic cardiomyopathy, clinical history of atherosclerosis, diabetes mellitus, older age and hemodialysis therapy.

Secemsky et al. [35] investigated $\mathrm{T}$ wave alternans and temporal relationship with dialysis sessions. They found a high prevalence of abnormal $\mathrm{T}$ wave alternans; however, there was not a striking temporal relationship with dialysis timing. In a randomized controlled intervention study, Kouidi et al. [36] investigated the effect of exercise training on noninvasive cardiac measures including $\mathrm{T}$ wave alternans. There was no significant improvement in positive $\mathrm{T}$ wave alternans in dialysis patients, possibly due to a small number of participants in the study. Currently there is no study in the literature examining the predictive value of abnormal $\mathrm{T}$ wave alternans on SCD in a longitudinal fashion.

\section{Late Potentials}

Signal-averaged ECG seeks to detect the occurrence of late activation within the myocardium (late potentials) noninvasively via surface ECG electrodes [37]. Late potentials represent areas of slow and abnormal ventricular activation, which increase the risk of re-entrant malignant ventricular arrhythmias. Morales et al. [38] showed that one fourth of dialysis patients had evidence of late potentials in signal-averaged ECG at baseline. Despite its high negative predictive value, this risk marker has not been studied in ESRD patients to date.

\section{Other Risk Factors}

A number of clinical and laboratory parameters have been recognized as risk predictors of SCD in patients with CKD (fig. 1). Some of these factors deserve further attention.

CKD is now recognized as an inflammatory condition. Despite this fact, few studies specifically investigated the role of increased inflammation in SCD. Parekh et al. [39] re-examined the cohort of 1,041 dialysis patients of the CHOICE study. During 2.5 years of follow-up, $22 \%$ of all mortality was due to SCD. The authors found that decreased albumin, elevated hsCRP and IL-6 levels were associated with an increased risk of SCD independent of traditional cardiovascular risk factors. Genovesi et al. [4] also showed an association between SCD and elevated CRP levels in maintenance hemodialysis patients. Given the high frequency of inflammation in the ESRD population, more studies are frankly needed.

Drechsler et al. [40] evaluated data of the 4D study in which they measured $25(\mathrm{OH})$ vitamin D levels of 1,108 diabetic maintenance hemodialysis patients. They showed that patients with severe vitamin $\mathrm{D}$ deficiency $[25(\mathrm{OH})$ vitamin $\mathrm{D} \leq 25 \mathrm{nmol} / \mathrm{l}]$ had a 3 -fold higher risk of SCD compared with those with sufficient $25(\mathrm{OH})$ vitamin D levels ( $>75 \mathrm{nmol} / \mathrm{l})$. Notably, the association was independent of known traditional cardiovascular risk factors. N-terminal pro-brain type natriuretic peptide has been proven to be a valuable biomarker for predicting cardiac events and mortality in the hemodialysis population [41]. Paniagua et al. [42] showed that N-terminal pro-brain type natriuretic peptide is a reliable predictor of death risk independently of the effect of dialysis modality on fluid volume control, and the presence of other clinical and biochemical markers recognized as risk factors for all-cause and cardiovascular mortality. However, in another study it was demonstrated that N-terminal pro-brain type natriuretic peptide was not associated with cardiac dysfunction but was dependent on factors associated with volume overload and malnutrition in hemodialysis patients [43]. It is plausible to think that, whether as a marker of cardiac dysfunction or of volume overload, both of which increase the risk of cardiac mortality, $\mathrm{N}$-terminal pro-brain type natriuretic peptide is a candidate marker to be used possibly in combination with others to predict the future risk of SCD in hemodialysis patients. 
Fig. 1. The risk assessment of SCD in CKD. SAECG $=$ Signal-averaged ECG.

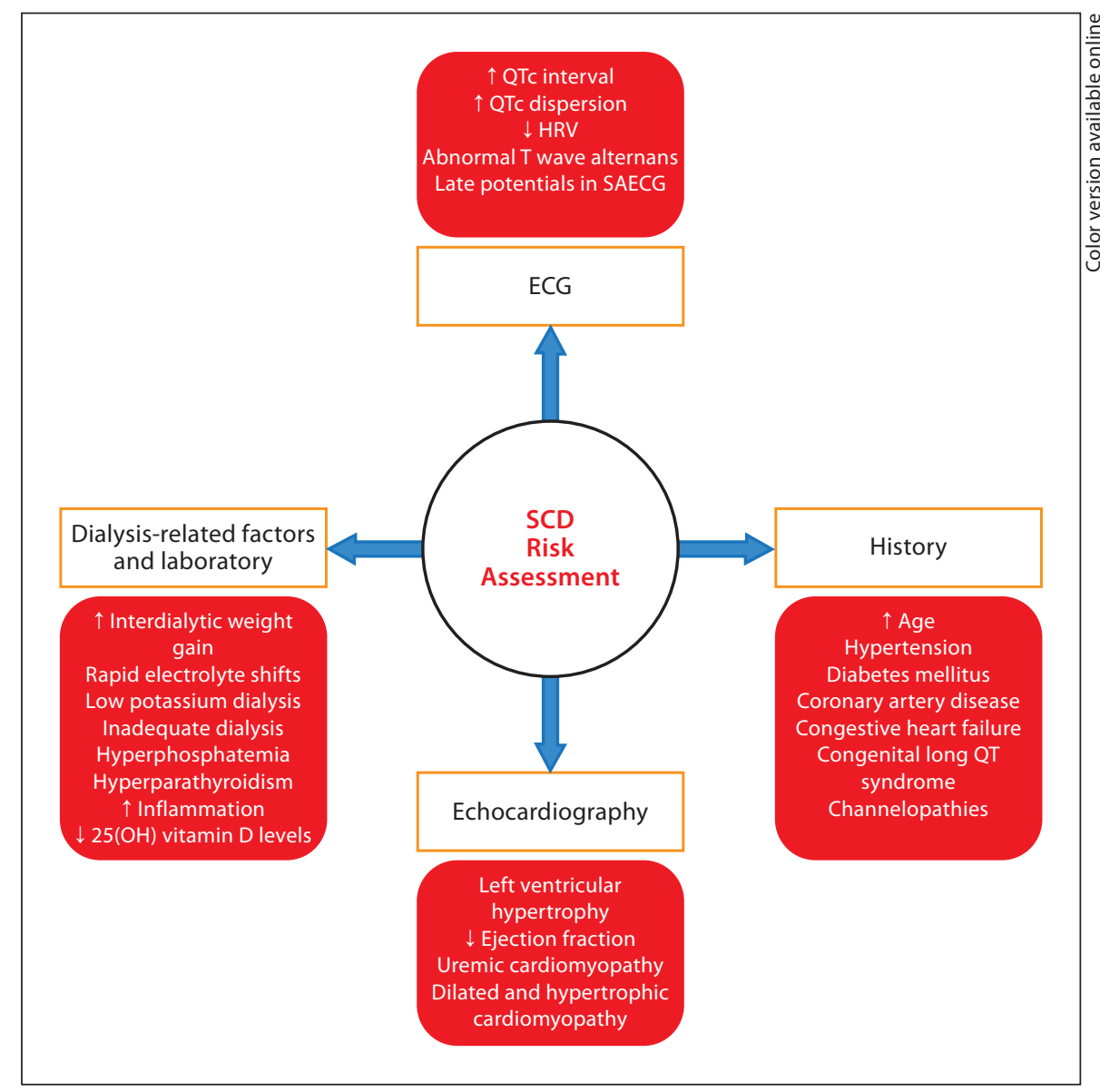

\section{Preventive Measures in SCD}

Given the dismal prognosis of survivors of SCD, accurate prediction of the risk of SCD in a given patient is of paramount importance. However, the complex and dynamic nature of SCD poses a challenge for early identification of risk factors. In addition, the various risk markers identified so far look at different aspects of increased risk. Thus, none of the risk factors may satisfactorily predict future development of SCD per se. Once a patient is deemed to be at high risk of developing SCD, the second step is to take effective measures to prevent the occurrence of the catastrophic event.

A number of interventions have been found to be effective to some extent in the prevention of SCD. In our opinion, until a single or a set of measures are found that are significantly effective in the prevention of SCD, the primary goal should be to deal with individual high-risk features of a given patient in terms of SCD, for instance, the proper management of anemia and calcium-phos- phorus metabolism, frequent (and adequate) dialysis, avoidance of low potassium dialysate, achieving normal blood pressures and normal glycemic control and so on (fig. 2). In patients with specific high-risk features, such as very low ejection fraction and severe cardiomyopathy, special measures such as an implantable cardioverter defibrillator (ICD) could be applied. The recent review by Passman and Herzog [44] reminds us that proof of the efficacy of either $\beta$-blockade or implantable devices is missing in ESRD patients.

\section{$\beta$-Blocker Therapy}

$\beta$-Blockers are underutilized in dialysis patients despite their well-defined beneficial role in hypertension and after myocardial infarction [45]. $\beta$-Blockers are also useful in ameliorating increased sympathetic nervous system activity in dialysis patients. No study has specifically evaluated the role of $\beta$-blocker therapy in SCD in patients with CKD. However, Cice et al. [46] showed a significant mortality benefit with the use of carvedilol 


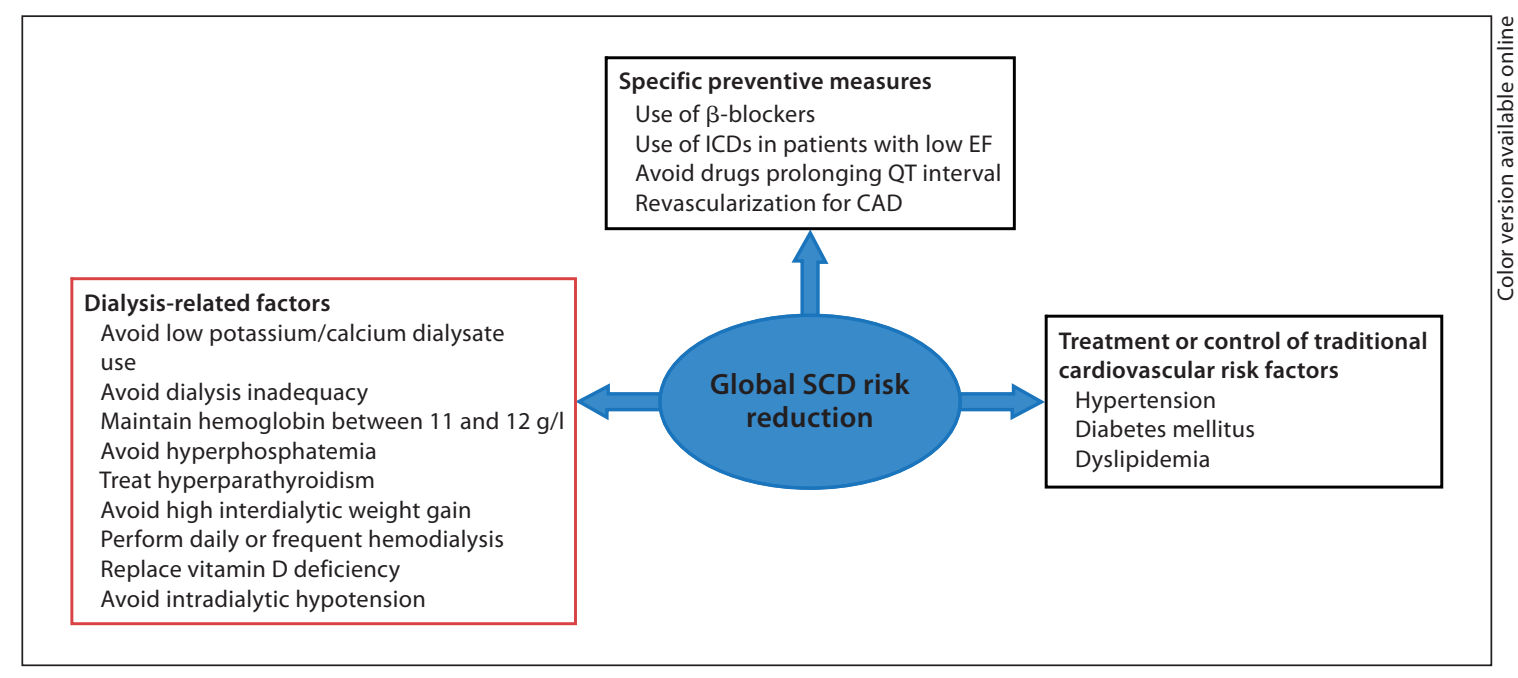

Fig. 2. Prevention of SCD in CKD. EF = Ejection fraction; CAD = coronary artery disease.

while another study showed mortality benefit when $\beta$ blockers were prescribed at the time of cardiac arrest [47]. In a very recent study in which data of the CAPRICORN and COPERNICUS studies were re-evaluated, the investigators found that carvedilol therapy was associated with a decrease in all-cause, cardiovascular, and heart failure mortality but not with SCD [48].

\section{Implantable Cardioverter Defibrillator}

Several trials in various patient groups to date have shown that ICD therapy is superior to medical therapy in primary and secondary prevention of all-cause mortality [45]. However, there are insufficient data to suppose that the same is the case for the CKD population because of the exclusion of patients with CKD from major clinical ICD trials [45]. A recent meta-analysis by Sakhuja et al. [49] concluded that even in those with ICDs there is still a 2.7-fold increased mortality risk in patients who receive dialysis compared with those who do not. The results also showed superiority of ICD implantation over $\beta$-blocker therapy. However, of 2,516 patients evaluated, only 89 patients were receiving dialysis. As pointed out by many reviewers, this area is desperately in need of well-conducted randomized controlled trials [44].

Unfortunately, the presence of CKD had a negative impact on patients who are already implanted with an ICD. Alla et al. [50] demonstrated that mortality risk is inversely proportional to glomerular filtration rate. Even moderate renal dysfunction increased all-cause mortality in CKD patients with an ICD. The authors also found that severe but not moderate CKD was an independent predictor of time to first appropriate ICD shock. With a similar retrospective design, Cheema et al. [51] showed that the mortality rate was higher in patients with an estimated glomerular filtration rate of $<60 \mathrm{ml} / \mathrm{min}$ and in those with ESRD on hemodialysis than in patients with an estimated glomerular filtration rate of $>60 \mathrm{ml} / \mathrm{min}$. The SCD rate was also found to be higher in the patients with ESRD (50\%) than in CKD patients not on dialysis (10\%). Khan et al. [52] found that ICD implantation did not increase survival in patients who were receiving dialysis but survival was significantly better in patients with predialytic CKD.

Considering the limited number of patients included in these studies, to determine the definitive role of ICD in patients with CKD and ESRD, larger longitudinal studies are clearly needed. The ICD-2 study may answer some of the questions pertaining to the optimal use of ICDs in this high-risk population [53].

\section{Conclusions}

SCD remains a major challenge in 2011 and our clinical predictive skill is limited. Coronary artery disease and dilated low left ventricular ejection fraction are most powerful, but not sufficiently specific in the predictive value to allow for a valid and useful risk stratification approach, and, in the absence of a clear-cut intervention, there will continue to be confusion amongst nephrolo- 
gists about whom to try to protect, when, and with what. It is a damning indictment of lack of focus and understanding of the major causes of mortality in subjects with ESRD that in 2011 we cannot provide complete answers to these burning questions. It is of paramount importance now that we test a variety of predictive tools using incident dialysis patients, and then a variety of interven- tional approaches, from altered dialysis practices, to altered drug therapies, to novel approaches which directly target the abnormal myocardium. Ultimately though, prevention is much better than cure, so careful attention to the many factors that can promote small and large vessel disease, as well as dilated cardiomyopathy remains the major goal for good integrated dialysis care.

\section{References}

1 Collins AJ, Foley RN, Herzog C, Chavers B, Gilbertson D, Ishani A, et al: United States Renal Data System 2008 Annual Data Report. Am J Kidney Dis 2009;53(1 suppl):S1S374.

$>2$ Karnik JA, Young BS, Lew NL, Herget M, Dubinsky C, Lazarus JM, et al: Cardiac arrest and sudden death in dialysis units. Kidney Int 2001;60:350-357.

$>3$ Saravanan P, Davidson NC: Risk assessment for sudden cardiac death in dialysis patients. Circ Arrhythm Electrophysiol 2010;3:553559.

4 Genovesi S, Valsecchi MG, Rossi E, Pogliani D, Acquistapace I, De Cristofaro V, et al: Sudden death and associated factors in a historical cohort of chronic haemodialysis patients. Nephrol Dial Transplant 2009;24: 2529-2536.

$>5$ Chugh SS: Early identification of risk factors for sudden cardiac death. Nat Rev Cardiol 2010;7:318-326.

-6 Herzog CA, Mangrum JM, Passman R: Sudden cardiac death and dialysis patients. Semin Dial 2008;21:300-307.

7 Mark PB, Johnston N, Groenning BA, Foster JE, Blyth KG, Martin TN, et al: Redefinition of uremic cardiomyopathy by contrast-enhanced cardiac magnetic resonance imaging. Kidney Int 2006;69:1839-1845.

$\checkmark 8$ Chen PS, Chou CC, Tan AY, Zhou S, Fishbein MC, Hwang C, et al: The mechanisms of atrial fibrillation. J Cardiovasc Electrophysiol 2006;17(suppl 3):S2-S7.

$>9$ Kanbay M, Afsar B, Goldsmith D, Covic A: Sudden death in hemodialysis: an update. Blood Purif 2010;30:135-145.

10 Ritz E, Wanner C: The challenge of sudden death in dialysis patients. Clin J Am Soc Nephrol 2008;3:920-929.

-11 McIntyre CW: Haemodialysis-induced myocardial stunning in chronic kidney disease - a new aspect of cardiovascular disease. Blood Purif 2010;29:105-110.

$\checkmark 12$ Burton JO, Jefferies HJ, Selby NM, McIntyre CW: Hemodialysis-induced repetitive myocardial injury results in global and segmental reduction in systolic cardiac function. Clin J Am Soc Nephrol 2009;4:1925-1931.
13 Burton JO, Jefferies HJ, Selby NM, McIntyre CW: Hemodialysis-induced cardiac injury: determinants and associated outcomes. Clin J Am Soc Nephrol 2009;4:914-920.

14 Perl J, Chan CT: Timing of sudden death relative to the hemodialysis procedure. Nat Clin Pract Nephrol 2006;2:668-669.

15 Pun PH, Lehrich RW, Honeycutt EF, Herzog CA, Middleton JP: Modifiable risk factors associated with sudden cardiac arrest within hemodialysis clinics. Kidney Int 2011;79: 218-227.

16 Ganesh SK, Stack AG, Levin NW, HulbertShearon T, Port FK: Association of elevated serum $\mathrm{PO}(4), \mathrm{Ca} \times \mathrm{PO}(4)$ product, and parathyroid hormone with cardiac mortality risk in chronic hemodialysis patients. J Am Soc Nephrol 2001;12:2131-2138.

- 17 Bozbas H, Atar I, Yildirir A, Ozgul A, Uyar M, Ozdemir N, et al: Prevalence and predictors of arrhythmia in end stage renal disease patients on hemodialysis. Ren Fail 2007;29: 331-339.

18 Wu VC, Lin LY, Wu KD: QT interval dispersion in dialysis patients. Nephrology (Carlton) $2005 ; 10: 109-112$.

19 Morris ST, Galiatsou E, Stewart GA, Rodger RS, Jardine AG: QT dispersion before and after hemodialysis. J Am Soc Nephrol 1999;10: 160-163.

20 Beaubien ER, Pylypchuk GB, Akhtar J, Biem HJ: Value of corrected QT interval dispersion in identifying patients initiating dialysis at increased risk of total and cardiovascular mortality. Am J Kidney Dis 2002;39:834842 .

21 Di Iorio BR, Bortone S, Piscopo C, Grimaldi P, Cucciniello E, D’Avanzo E, et al: Cardiac vascular calcification and QT interval in ESRD patients: is there a link? Blood Purif 2006;24:451-459.

$22 \mathrm{Wu}$ VC, Huang JW, Wu MS, Chin CY, Chiang FT, Liu YB, et al: The effect of iron stores on corrected QT dispersion in patients undergoing peritoneal dialysis. Am J Kidney Dis 2004;44:720-728.

23 Kim HW, Park CW, Shin YS, Kim YS, Shin SJ, Choi EJ, et al: Calcitriol regresses cardiac hypertrophy and QT dispersion in secondary hyperparathyroidism on hemodialysis. Nephron Clin Pract 2006;102:c21-c29.
24 Genovesi S, Dossi C, Vigano MR, Galbiati E, Prolo F, Stella A, et al: Electrolyte concentration during haemodialysis and QT interval prolongation in uraemic patients. Europace 2008;10:771-777.

25 Ranpuria R, Hall M, Chan CT, Unruh M: Heart rate variability (HRV) in kidney failure: measurement and consequences of reduced HRV. Nephrol Dial Transplant 2008; 23:444-449.

26 Reed MJ, Robertson CE, Addison PS: Heart rate variability measurements and the prediction of ventricular arrhythmias. QJM 2005;98:87-95.

27 Nishimura M, Tokoro T, Nishida M, Hashimoto T, Kobayashi H, Yamazaki S, et al: Sympathetic overactivity and sudden cardiac death among hemodialysis patients with left ventricular hypertrophy. Int J Cardiol 2010;142:80-86.

28 Oikawa K, Ishihara R, Maeda T, Yamaguchi K, Koike A, Kawaguchi H, et al: Prognostic value of heart rate variability in patients with renal failure on hemodialysis. Int J Cardiol 2009;131:370-377.

-29 Roumelioti ME, Ranpuria R, Hall M, Hotchkiss JR, Chan CT, Unruh ML, et al: Abnormal nocturnal heart rate variability response among chronic kidney disease and dialysis patients during wakefulness and sleep. Nephrol Dial Transplant 2010;25:3733-3741.

30 Furuland H, Linde T, Englund A, Wikstrom B: Heart rate variability is decreased in chronic kidney disease but may improve with hemoglobin normalization. J Nephrol 2008;21:45-52.

31 Yang YW, Wu CH, Tsai MK, Kuo TB, Yang CC, Lee PH: Heart rate variability during hemodialysis and following renal transplantation. Transplant Proc 2010;42:1637-1640.

32 Rubinger D, Backenroth R, Sapoznikov D: Restoration of baroreflex function in patients with end-stage renal disease after renal transplantation. Nephrol Dial Transplant 2009;24:1305-1313.

33 Friedman AN, Groh WJ, Das M: A pilot study in hemodialysis of an electrophysiological tool to measure sudden cardiac death risk. Clin Nephrol 2007;68:159-164. 
34 Patel RK, Mark PB, Halliday C, Steedman T, Dargie HJ, Cobbe SM, et al: Microvolt Twave alternans in end-stage renal disease patients - associations with uremic cardiomyopathy. Clin J Am Soc Nephrol, E-pub ahead of print.

35 Secemsky EA, Verrier RL, Cooke G, Ghossein C, Subacius H, Manuchehry A, et al: High prevalence of cardiac autonomic dysfunction and T-wave alternans in dialysis patients. Heart Rhythm, E-pub ahead of print.

36 Kouidi EJ, Grekas DM, Deligiannis AP: Effects of exercise training on noninvasive cardiac measures in patients undergoing longterm hemodialysis: a randomized controlled trial. Am J Kidney Dis 2009;54:511-521.

37 Stein KM: Noninvasive risk stratification for sudden death: signal-averaged electrocardiography, nonsustained ventricular tachycardia, heart rate variability, baroreflex sensitivity, and QRS duration. Prog Cardiovasc Dis 2008;51:106-117.

38 Morales MA, Gremigni C, Dattolo P, Piacenti M, Cerrai T, Fazi A, et al: Signal-averaged ECG abnormalities in haemodialysis patients. Role of dialysis. Nephrol Dial Transplant 1998;13:668-673.

- 39 Parekh RS, Plantinga LC, Kao WH, Meoni LA, Jaar BG, Fink NE, et al: The association of sudden cardiac death with inflammation and other traditional risk factors. Kidney Int 2008;74:1335-1342.

-40 Drechsler C, Pilz S, Obermayer-Pietsch B, Verduijn M, Tomaschitz A, Krane V, et al: Vitamin D deficiency is associated with sudden cardiac death, combined cardiovascular events, and mortality in haemodialysis patients. Eur Heart J 2010;31:2253-2261.
41 Winkler K, Wanner C, Drechsler C, Lilienthal J, Marz W, Krane V: Change in N-terminal-pro-B-type-natriuretic-peptide and the risk of sudden death, stroke, myocardial infarction, and all-cause mortality in diabetic dialysis patients. Eur Heart J 2008;29:20922099.

42 Paniagua R, Ventura MD, Avila-Diaz M, Hinojosa-Heredia H, Mendez-Duran A, CuetoManzano A, et al: NT-proBNP, fluid volume overload and dialysis modality are independent predictors of mortality in ESRD patients. Nephrol Dial Transplant 2010;25:551557.

43 Booth J, Pinney J, Davenport A: N-terminal proBNP - marker of cardiac dysfunction, fluid overload, or malnutrition in hemodialysis patients? Clin J Am Soc Nephrol 2010 5:1036-1040

44 Passman R, Herzog CA: End-stage renal disease: sudden cardiac death: stratifying risk in dialysis patients. Nat Rev Nephrol 2011;7: $133-135$.

45 de Bie MK, van Dam B, Gaasbeek A, van Buren $M$, van Erven L, Bax JJ, et al: The current status of interventions aiming at reducing sudden cardiac death in dialysis patients. Eur Heart J 2009;30:1559-1564.

46 Cice G, Ferrara L, D’Andrea A, D’Isa S, Di Benedetto A, Cittadini A, et al: Carvedilol increases two-year survivalin dialysis patients with dilated cardiomyopathy: a prospective, placebo-controlled trial. J Am Coll Cardiol 2003;41:1438-1444.

47 Pun PH, Lehrich RW, Smith SR, Middleton JP: Predictors of survival after cardiac arrest in outpatient hemodialysis clinics. Clin J Am Soc Nephrol 2007;2:491-500.
48 Wali RK, Iyengar M, Beck GJ, Chartyan DM, Chonchol M, Lukas MA, et al: Efficacy and safety of carvedilol in treatment of heart failure with chronic kidney disease: a metaanalysis of randomized trials. Circ Heart Fail 2011;4:18-26.

49 Sakhuja R, Keebler M, Lai TS, McLaughlin Gavin C, Thakur R, Bhatt DL: Meta-analysis of mortality in dialysis patients with an implantable cardioverter defibrillator. Am J Cardiol 2009; 103:735-741.

50 Alla VM, Anand K, Hundal M, Chen A, Karnam $S$, Hee $T$, et al: Impact of moderate to severe renal impairment on mortality and appropriate shocks in patients with implantable cardioverter defibrillators. Cardiol Res Pract 2010;2010:150285.

51 Cheema A, Singh T, Kanwar M, Chilukuri K, Maria V, Saleem F, et al: Chronic kidney disease and mortality in implantable cardioverter-defibrillator recipients. Cardiol Res Pract 2010;2010:989261.

-52 Khan F, Adelstein E, Saba S: Implantable cardioverter defibrillators confer survival benefit in patients with renal insufficiency but not in dialysis-dependent patients. J Interv Card Electrophysiol 2010;28:117-123.

53 de Bie MK, Lekkerkerker JC, van Dam B, Gaasbeek A, van Buren M, Putter H, et al: Prevention of sudden cardiac death: rationale and design of the Implantable Cardioverter Defibrillators in Dialysis patients (ICD2) Trial - a prospective pilot study. Curr Med Res Opin 2008;24:2151-2157. 